\title{
Direct Determination of Uric Acid in Human Serum Samples Using Polypyrrole Nanoelectrode Ensembles
}

\author{
Guangming Yang, Lin Tan, Ya Shi, Suiping Wang, ${ }^{\dagger}$ Xuxiao Lı, Huiping Bai, and Yunhui Yang’ \\ College of Chemistry and Chemical Engineering, Iunnan Kormal Universitv, Kumming 650092, P.R. China \\ E-mail: whitiz002ovahoo.com.cn \\ State Key Laboratory of Chemo Biosensing and Chemometrics, Hunan University, Changsha H10082, P.R. China \\ Received October 20, 2008, Accepted December 18, 2008
}

\begin{abstract}
Polypyrrole (PPy) nanotubes have been synthesized by chemical oxidative polymerization of pyrrole within the pores of polycarbonate membrane using the technology of diffusion of solutes. The nanotubes array prepared by the proposed method can be considered as nanoelectrode ensembles (NEEs). An amperometric uric acid sensor based on PPy NEEs has been developed and used for determination of uric acid in human serum samples. The electrode can direct response to uric acid at potential of $0.60 \mathrm{~V} \mathrm{vs.} \mathrm{SCE} \mathrm{with} \mathrm{wide} \mathrm{linear} \mathrm{range} \mathrm{of} 1.52 \times 10^{\circ 6}$ to $1.54 \times 10^{-6} \mathrm{M}$. The detection limit is $3.02 \times 10^{-1} \mathrm{M}$. This sensor has been used to determine uric acid in real serum samples. PPy NEEs is thought of as a good application in the foreground.
\end{abstract}

Key Words: Uric acid. Sensor. Polypy rrole nanotubes. Polycarbonate membrane. Diffusion

\section{Introduction}

Nanostructured conductive polymers have attracted growing attention due to their potential applications in biosensors. ${ }^{1 .}$ biomedicines. ${ }^{3}$ actuators. ${ }^{4}$ and fuel cell ${ }^{5.6}$ Nanostructured polypy rrole (PPy) is one of the most extensively used conducting polymers in design of enzyme sensors. ${ }^{-5}$ immunosensor ${ }^{10}$ and DNA sensor" ${ }^{11}$ because of its high environmental stability. electronic conductivity ion exchange capacity and biocompatibility. Up to now, nanostructured PPy (nanofibers. nanotubes. nanowires) with various morphologies have been synthesized by electrochemical methods and chemical methods combining the technology of solid template, self-assembly, surfactant. molecularly print. For instance. Martin et al. ${ }^{127 i}$ have investigated the electrochemical and chemical template synthesis of PPy within the pores of polycarbonate membranes. Hernandez et al. ${ }^{14}$ have synthesized protein-functionalized Gold-PPy-Gold segmented nanowires by' using porous aluminum oxide as a template. Chen $e t \mathrm{al} .{ }^{15}$ have used oriented carbon nanotubes as the template to electrochemically deposit a thin PPy coating on the surface of the carbon nanotubes. PPy nanowire networks have been synthesized in high yield by chemical oxidative polymerization of pyrrole in the presence of hexadecyltrimethylammonium bromide (HTAB) and organic diacids. ${ }^{16}$ Nanostructured PPys with controlled morphologies have been synthesized on atomically flat surfaces using adsorbed surfactant molecules as template. ${ }^{17}$ However. most of these syythesized methods are time-consuming. ${ }^{15.16}$ complex $^{14.17}$ and not easy to synthesize oriented nanostructures. ${ }^{12.16}$ The method of synthesizing nanostnictured PPy with simple procedure and oriented nanostnictures is still in need of exploration.

The development of simple and rapid methods for the determination of uric acid in urine and serum is attracted because the abnormal levels of uric acid in urine and senum are symptoms of several diseases like gout. hyperuricaemia and Lesch-Nyhan syndrome. Different methods have been reported for the detection and estimation of uric acid levels, including enzymatic methods. ${ }^{18} \mathrm{HPLC}^{19} \mathrm{HPCE}^{2 / 1}$ and electrochemistry methods. ${ }^{2.22}$ The enzymatic methods for determination of uric acid is promising due to their high selectivity. but this method inherently more expensive, need more technology of the enzymatic immobility. HPLC and HPCE are sensitive. but they are time-consuming and complex. Alternatively, the determination of uric acid by electrochemical methods have received much interest because they are more selective, less expensive and less time consuming than those based on enzymatic methods. HPLC and HPCE.

In this study. PPy nanotubes have been synthesized by chemical oxidative polymerization of py rrole in the presence of polycarbonate membrane using the technology of diffusion of solutes. The diameter of PPy nanotubes is about $200 \mathrm{~nm}$ and the length is about $1.8 \mu \mathrm{m}$. The nanotubes array prepared by the proposed method can be considered as nanoelectrode ensembles (NEEs). An amperometric uric acid sensor based on PPy NEEs has been developed and used for determination of uric acid in human serum samples. The as-prepared sensor displays high sensitivity, quick response to uric acid. good stability and wide linear range. Besides. the lifetime of this sensor is much longer than that of biosensor based on uricase.

\section{Experimental Section}

Apparatus and reagents. Cyclic voltammetric and amperometric measurements were carried out on XJP- $82 \mathrm{l}(\mathrm{C})$ polarograph (Jiangsu, China). Scanning electron microscopy (SEM) analy'sis was performed by using XL 30ESEM-TMP microscope (Philips Ltd., Holand). The three-electrode cell $(10 \mathrm{~mL})$ was constituted of the PPy NEEs modified glassy carbon (GC) electrode as the working electrode, a saturated calomel electrode (SCE) as reference electrode and platinum foil electrode as counter electrode. All potentials were measured and reported versus the SCE.

Nucleopore PC $(0.2 \mu \mathrm{m})$ membrane was provided by 
Whatman (Anodisc 47.0.2 $\mu \mathrm{m}$ ); uric acid was purchased from Sigma (USA). The pyrrole monomer was purified by distillation. The other chemicals, such as ammonium persulfate ( $\left(\mathrm{NH}_{4}\right)_{2} \mathrm{~S}_{2} \mathrm{O}_{8}$, APS). chloroform $\left(\mathrm{CHCl}_{3}\right)$, ethanol $\left(\mathrm{C}_{2} \mathrm{H}_{3} \mathrm{OH}\right)$. were of analy tical-reagent grade and used as received without further purification. and doubly distilled water was used throughout. The supporting electroly te was $0.2 \mathrm{M}$ borate buffer solution, which was prepared with $\mathrm{H}_{3} \mathrm{BO}_{3}$ and $\mathrm{Na}_{2} \mathrm{~B}_{4} \mathrm{O} * 10$ $\mathrm{H}_{2} \mathrm{O}$.

Synthesis of polypymole nanotubes. PPy nanotubes have been synthesized by diffusion of solutes has been reported. ${ }^{13}$ In this paper. the device was simplified as shown in Fig. 1. A beaker $(25 \mathrm{~mL})$ was divided into two portions by the interlayer using epoxy resin. The $\mathrm{PC}$ membrane was adhibited onto the hole in the interlayer. The molar ratio of APS to py rrole was $1: 1{ }^{16}$ The solution of pyrrole $(10 \mathrm{~mL} .0 .008 \mathrm{M})$ was added into one side. while the solution of ASP $(10 \mathrm{~mL}, 0.008 \mathrm{M})$ was added into another side at the same time. The height of two solutions was kept at the same level. After polymerization for 30 min at room temperature. the synthesis of PPy nanotubes was completed. Then the PC membrane was taken out and washed with deionized water.

Preparation of PPy NEEs / GC electrode. Glassy carbon (GC) electrode ( $3 \mathrm{~mm}$ diameter) was first polished with emery paper and alumina slurry. successively rinsed thoroughly with absolute alcohol and distilled water in ultrasonic bath. and dried in air.

Two pieces of PC membrane with PPys nanotubes with different polymerization time ( $30 \mathrm{~min}$ and $60 \mathrm{~min}$ ) were taken and attached down on the surface of GC electrode by the graphite conductive adhesive. then the edge of $\mathrm{PC}$ membrane was sealed using epoxy resin. After $3 \mathrm{~h}$, the PC membrane was dissolved by immersing the electrode in chloroform for 10 min and washed successively using ethanol and water. and dried in air. PPy NEEs / GC electrodes (polymerized for 30 and $60 \mathrm{~min}$ ) have been prepared by the process. A bare GC electrode ( $3 \mathrm{~mm}$ diameter), GC electrode modified by PC membrane with PPy before dissolved by chloroform and PPy NEEs / GC electrodes (polymerized 60 min) were used as comparisons.

\section{Results and Discussion}

Morphological characterization of the prepared PPy. Fig. 2 shows the morphologies of the PPy with different poly merization time characterized by scanning electron microscopy (SEM). Comparing with the PC membrane before polymerization (Fig. 2(a)), it can be concluded that the reaction of

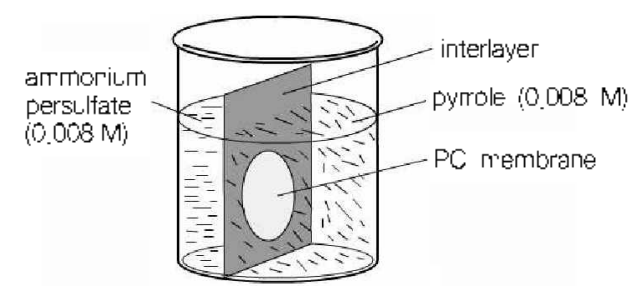

Figure 1. The illustration of the device for preparation of ordered polyprrrole nanotubes

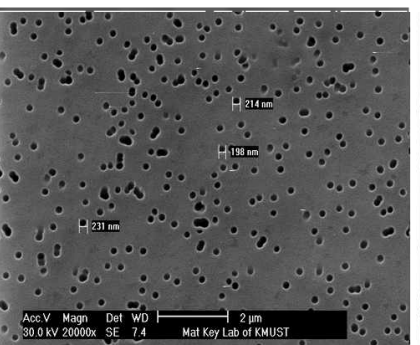

(a)

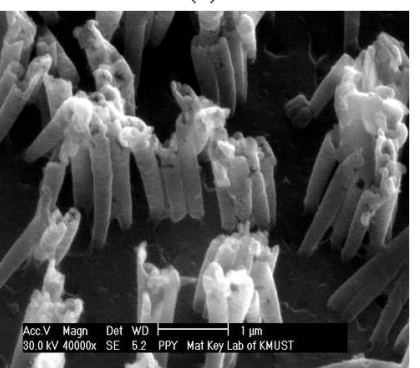

(c)

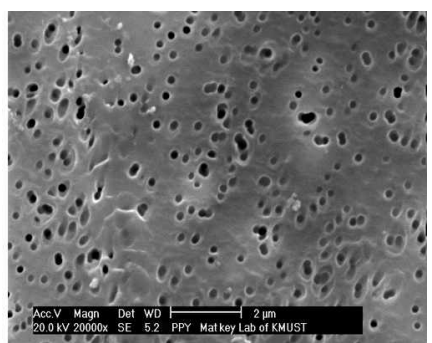

(b)

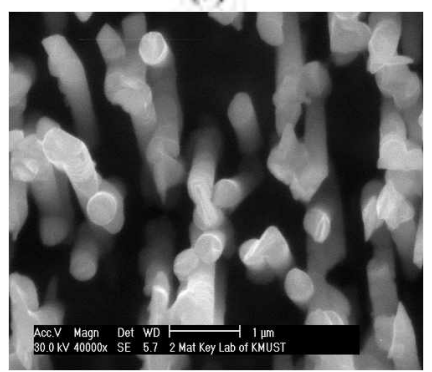

(d)
Figure 2. SEM images of the poly pyrrole: the PC membrane before polymerization (a), after polymerization for $3 \mathrm{~min}(\mathrm{~b}), 30 \mathrm{~min}(\mathrm{c})$ and $60 \mathrm{~min}(\mathrm{~d})$

polymerization can occur in the pore of the $\mathrm{PC}$ membrane after diffusion $3 \mathrm{~min}$ (Fig. 2(b)). After polymerization for 30 min. the PPy nanotubes were obtained by etching away the membrane. From Fig. 2(c). it can be seen that PPy nanotubes are hollow and vertically oriented with an average diameter about $200 \mathrm{~nm}$, which correspond to the size of the nanopore in the membrane. The length is about $1.8 \mu \mathrm{m}$. Each vertical nanotube can work as an individual nanoelectrode $e^{23.24}$ and entire nanotubes array can be considered as PPy NEEs. However, after polymerization for $60 \mathrm{minh}$. the morphologies of the PPys have been changed to solid nanotubes (Fig. 2(d)).

Effect of dissolved time of PC membrane. Fig. 3 describes the cyclic voltammograms of different electrodes with different dissolved time by chloroform in $0.2 \mathrm{M}$ borate buffer solution ( $\mathrm{pH} 7.4$ ) containing $0.80 \times 10^{-2} \mathrm{M}$ uric acid at $100 \mathrm{mVs}^{-1}$.

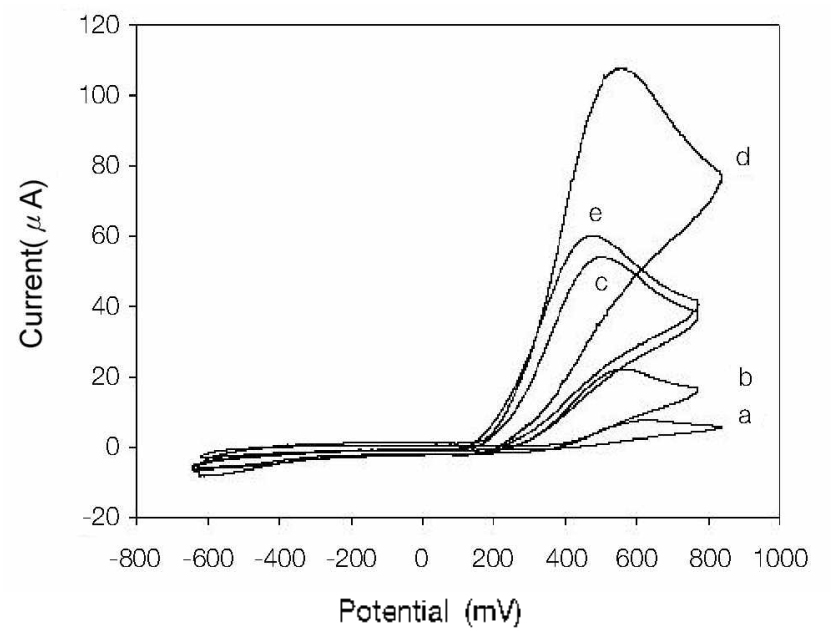

Figure 3. Cyclic voltammograms (CVs) of PPy NEEs / GC electrode dissolved by chloroform different time in $0.2 \mathrm{M}$ borate buffer solution ( $\mathrm{pH} 7.4$ ) containing $0.80 \times 10^{2} \mathrm{M}$ uric acid at $100 \mathrm{mV} / \mathrm{s}$ : (a) before dissolved, (b) dissolved $1 \mathrm{~min}$, (c) dissolved 5 mir, (d) dissolved $10 \mathrm{~min}$, (e) dissolved $15 \mathrm{~min}$. 
(a)

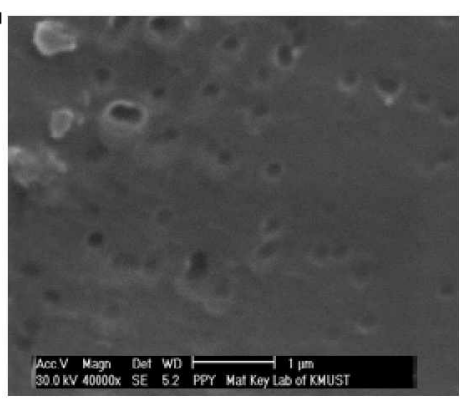

(b)

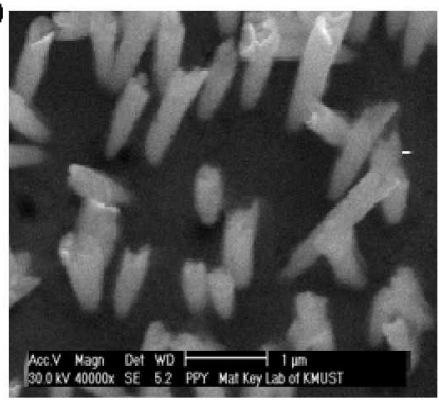

(c)

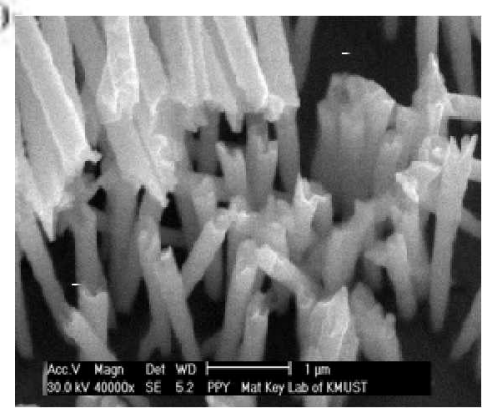

Figure 4. SEM inages of p electrodes modified by PC membrane with PPy with different dissolved time by chloroform: (a) before dissolved, (b) dissolved $5 \mathrm{~min}$, (c) dissolved $15 \mathrm{~min}$.

It can be seen that the current of PPy NEEs / GC electrode (polymerized for $30 \mathrm{~min}$ ) elevated as dissolved time increased. However. when dissolyed time excessed $10 \mathrm{~min}$, the current decreased. This fact can be ascribed that the bareness of PPy nanotubes increased with dissolved time increasing. But when dissolved time was too long. PC membrane was dissolved so completely that PPy nanotubes released from PC membrane were not vertically oriented, and the nanotubes array was destroyed. which lead to the lower current. Additionally, Fig. 4 illustrates the SEM of different electrodes with different dissolved time by chloroform (Fig. 4(a): before dissolved. (b): 5 min. (c): $15 \mathrm{~min}, 10 \mathrm{~min}$ see Fig. 2(c)) which clarifies this point. Therefore. the dissolved time of $10 \mathrm{~min}$ was adopted in the subsequent work.

Effect of PPy NEEs / GC electmde of catalysis to uric acid and the mechanism of the amperometric detection of uric acid Fig. 5 depicts the cyclic voltammograms of different electrodes in $0.2 \mathrm{M}$ borate buffer solution ( $\mathrm{pH} 7.4$ ) containing $0.80 \times 10^{-2} \mathrm{M}$ uric acid at $100 \mathrm{mVs}^{-1}$. It can be seen that the current of GC electrode modified by PC membrane with PPy before dissolved by chloroform (curve a) was lower than that of the bare GC electrode (curve b). PPy NEEs / GC electrodes (poly merized for $30 \mathrm{~min}$. hollow nanotubes) was larger than that of the bare GC electrode. electrode modified by PC membrane with PPy before dissolved by chloroform and PPy NEEs / GC electrodes (poly'merized $60 \mathrm{~min}$. solid nanotubes). Therefore, polymerization of $30 \mathrm{~min}$ was fixed for the rest of the experiments.

In our opinion, both the increase in current and the better reversibility are related to some specific electrocatalysis of PPy. ${ }^{-1}$ In fact. the PPy nanotubes can be oxidized electrochemically to $\mathrm{PPy}^{+}$, which then oxidizes uric acid. Fig. 6 clarifies this point. PPy NEEs / GC electrodes (polymerized for 30 min) have more PPy than the bare GC electrode and GC electrode modified by PC membrane with PPy before dissolved. Furthermore, PPy NEEs (hollow) can provide more surfaces containing $\mathrm{PPy}^{+}$than the PPy NEEs (solid). It is known that uric acid is oxidized in a two electron process to produce allantoin as shown in the following equation: ${ }^{\text {¿ }}$

$$
\text { 至 }
$$

Cyclic voltammetry chancterization. The cyclic voltammograms of uric acid at different electrodes were shown in
Fig. 6. It can be seen that the current of PPy NEEs / GC electrode in 0.2 M borate buffer solution ( $\mathrm{pH} 7.4$ ) containing $1.14 \times$ $10^{-2} \mathrm{M}$ uric acid was larger than that of the bare $\mathrm{GC}$ electrode due to the larger accessible surface area of the modified electrode. The increased response current at about $0.60 \mathrm{~V}$ indicated the response of the catalysis of PPy NEEs to uric acid was irreversible.

Typical cyclic voltanmogrants of PPy NEEs/GC electrode in $0.2 \mathrm{M}$ borate buffer solution ( $\mathrm{pH} 7.4$ ) containing $1.14 \times 10^{-2}$ $\mathrm{M}$ uric acid at different scan rates from 20 to $100 \mathrm{mVs}^{.1}$ were investigated (data not shown). The oxidation peak potentials of uric acid were observed to shift positively with the increase of scan rate. and the peak currents rose accordingly. Moreover. there was a good linear relationship between the peak currents of uric acid and the square root of scan rates. The linear regression equations were ip $=70.07+7.57 \mathrm{r}^{1: 2}\left(\mathrm{ip}: 10^{-6}\right.$ A. $\left.v: \mathrm{mVs}^{-1}, \mu: 0.997\right)$. showing typical diffusion-controlled electrochemical behavior.

Effect of the PPy NEEs on the response of electrode. Anperometric responses of bare GC and optimized PPy NEEs / $\mathrm{GC}$ electrode for successive injection of $0.5 \mathrm{mM}$ uric acid at $0.6 \mathrm{~V}$ in $10 \mathrm{~mL} 0.2 \mathrm{M}$ borate buffer solution ( $\mathrm{pH} 7.4)$ were investigated. The electrochemistry oxidation of uric acid can

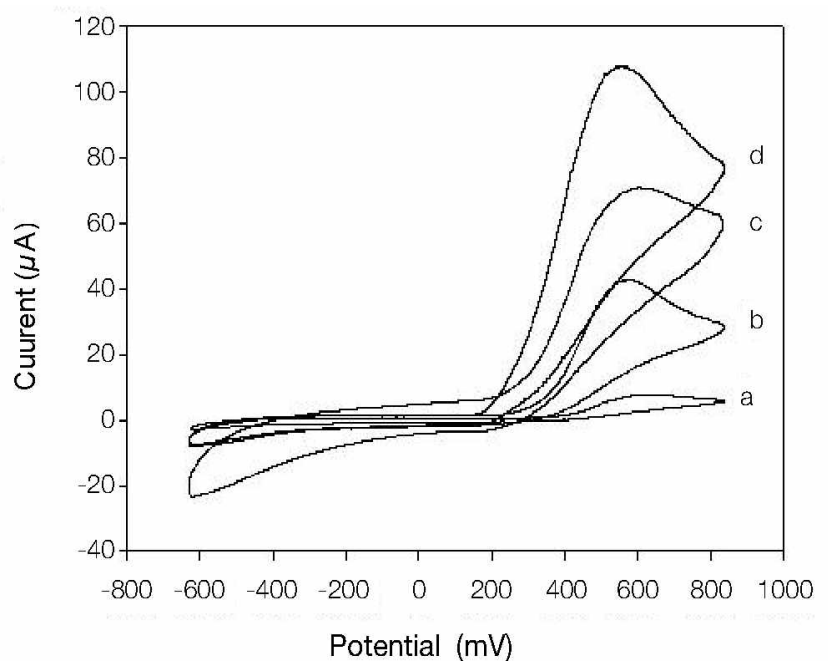

Figure 5. Cyclic voltammograms (CVs) of (a) electrode modified by PC membrane with PPy (before dissolved) (b) bare $\mathrm{GC}$ electrode, (c) PPy NEEs (solid nanotubes) / GC electrode and (d) the PPy NEEs (hollow nanotubes)/ GC electrode in $0.2 \mathrm{M}$ borate buffer solution $(\mathrm{pH} 7.4)$ containing $0.80 \times 10^{-2} \mathrm{M}$ uric acid at 100 nाVड 
occur both at PPy NEEs / GC electrode and bare GC electrode. To study the role of PPY NEEs. the responses of the electrode with and without PPy NEEs were studied. From Fig. 7, it can be seen that the sensitivity of PPy NEEs / GC electrode toward uric acid were better than that of bare GC electrode. indicating that PPy NEEs have better catalysis to uric acid.

Optimization of experimental variables. The experimental variables. which can affect the amperometric determination of uric acid. including the $\mathrm{pH}$ of the supporting electrolyte and applied potential. were investigated.

Effect of pH. The influence of the $\mathrm{pH}$ of the assay solution over the range 6.7 to 8.2 on the amperometric response of PPy NEEs / GC electrode to uric acid at a fixed concentration of $4.9 \mathrm{mM}$ in borate buffer solution at $0.6 \mathrm{~V}$ was investigated. The results of amperometric responses indicated that the optimum $\mathrm{pH}$ was 7.4 (data not shown). Therefore, $\mathrm{pH} 7.4$ was fixed for the rest of the experiments.

Effect of applied potential. The effect of applied potential on amperometric response of PPy NEEs / GC electrode was investigated in $10 \mathrm{~mL} 0.2 \mathrm{M}$ borate buffer solution ( $\mathrm{pH} \mathrm{7.4)}$

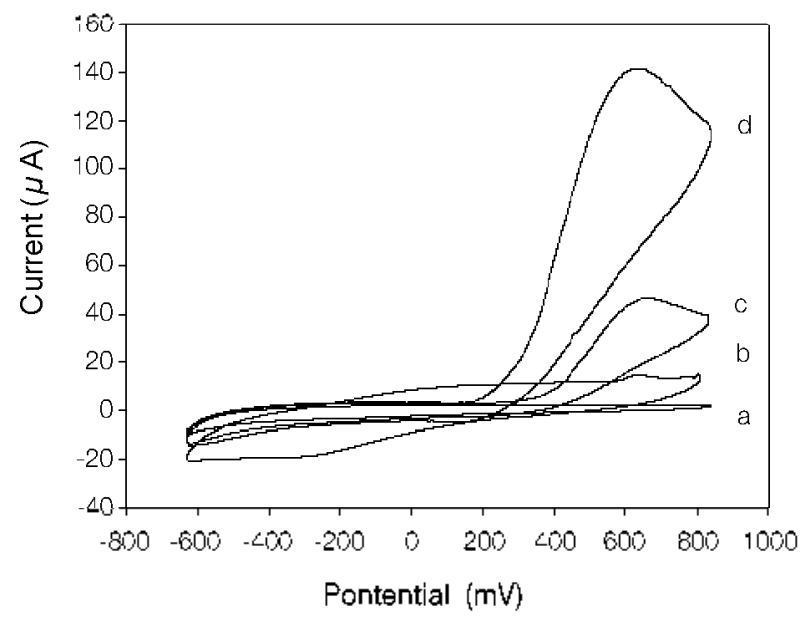

Figure 6. The cyclic voltanmograms of different electrodes in various solutions: (a) the bare GC electrode and (b) PPy NEEs / GC electrode both in borate buffer solution ( $\mathrm{pH} 7.4$ ): (c) the bare GC electrode and (d) PPy NEEs / GC electrode both in borate buffer solution $(\mathrm{pH} 7.4)$ containing $1.14 \times 10^{-2} \mathrm{M}$ uric acid.

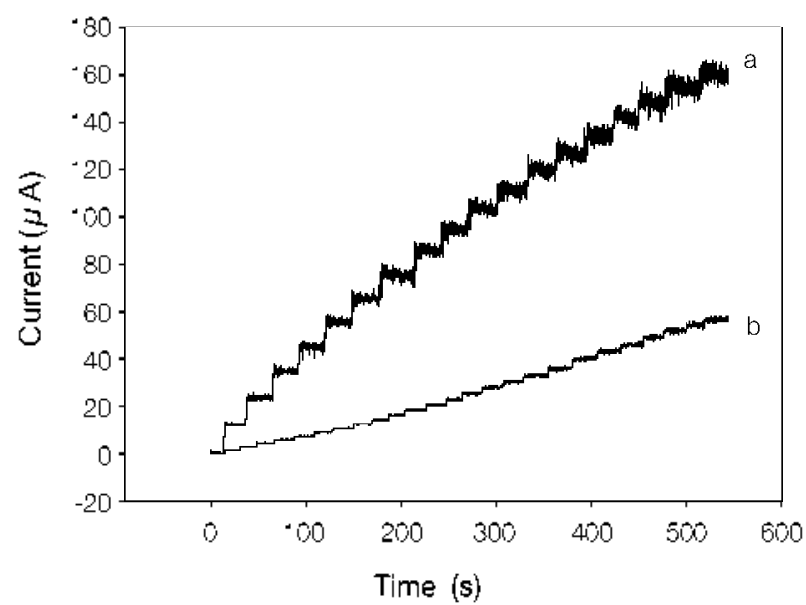

Figure 7. Amperometric response of PPy NEEs / GC electrode (a) and the bare $\mathrm{GC}$ electrode (b) to the successive addition of $0.5 \mathrm{mM}$ uric acid at $0.60 \mathrm{~V}$ in $10 \mathrm{~mL} 0.2 \mathrm{M}$ borate buffer solution ( $\mathrm{pH} 7.4$ ). containing $4.9 \mathrm{mM}$ uric acid was studied (data not shown). With the increasing of potential from 0.45 to $0.90 \mathrm{~V}$, the response current of the electrode increased significantly. To avoid interference at higher applied potentials, a potential of $0.60 \mathrm{~V}$ (vs. SCE) was selected as the applied potential for amperometric measurements.

Response characteristics of PPy NEEs / GC electiode. The calibration curve is shown in Fig. 8. The responses current increases as the uric acid concentration is elevated. Over a concentration range of $1.52 \times 10^{-6}$ to $1.54 \times 10^{-3} \mathrm{M}$. the electrode provided a linear response to uric acid with a good sensitivity of $0.452 \mathrm{~A} \mathrm{M}^{-1} \mathrm{~cm}^{-2}$. The linear equation could be described as follows: I $(\mu \mathrm{A})=0.4+3+28.73 \mathrm{C}(\mathrm{mM})$. with a correlation coefficient of 0.999 . and the detecting limit of is $3.02 \times 10^{-2} \mathrm{M}$. The linear range is vider than the previous results reported by Zlang $^{29}$ based on uricase biosensor. $\mathrm{Wu}^{23}$ and $\operatorname{Lin}^{23}$ with electrochemical methods. The detecting limit is lower than previous reports using uricase biosensor ${ }^{29}$ and electrochemical methods. ${ }^{21.23 .28 .3 i \text { i }}$

Interference. To assess the selectivity of PPy NEEs / GC electrode. twelve possible interferences in the presence of 4.9 $\mathrm{mM}$ uric acid were investigated which was shown in Table 1. Before treatment. the amperometric response ratio of ascorbic

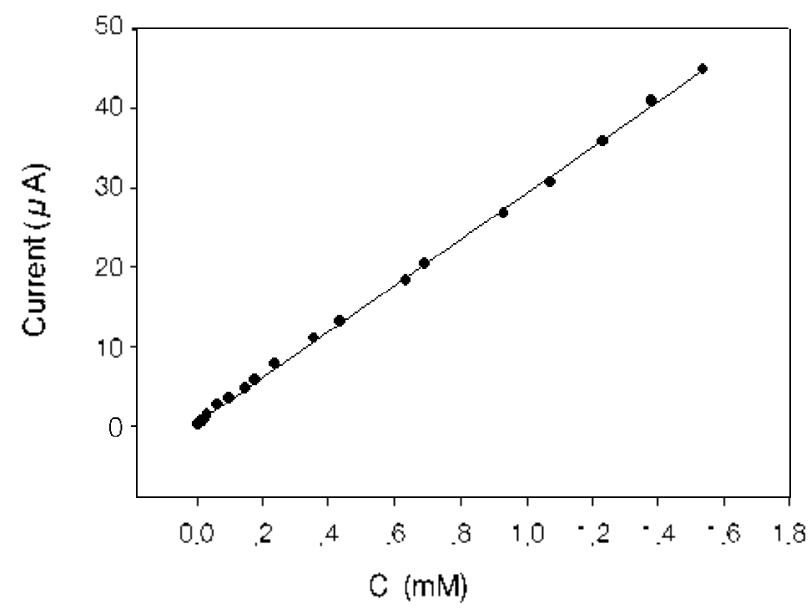

Figure 8. The calibration curves of PPy NEEs/GC electrode

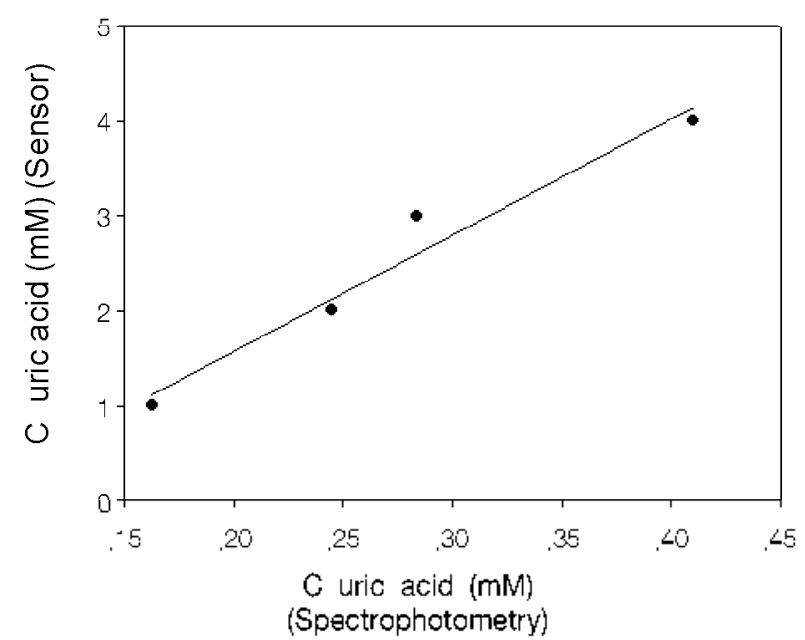

Figure 9. Comparison of the uric acid contents in serum sample determuned with PPY NEEs / GC electrode and spectrophotometry. 
Table 1. Possible interferences tested with PPy NEEs / GC electrode

\begin{tabular}{|c|c|c|}
\hline & 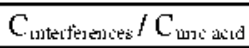 & $\mathrm{i}_{\text {wytestertuce }} / \mathrm{i}_{\text {wว acul }}$ \\
\hline citric acid & 4.4 & 0.12 \\
\hline glucose & 7.4 & 0.03 \\
\hline alanine & 3.4 & 0.08 \\
\hline ascorbic acid & 3.4 & $0.15^{\sigma}$ \\
\hline tartaric acid & 3.4 & 0.07 \\
\hline oxalic acid & 3.4 & 0.10 \\
\hline glutamic acid & 3.4 & 0.03 \\
\hline pyruvic acid & 3.4 & 0.1 \\
\hline $\mathrm{Pb}^{2+}$ & 2.2 & 0.03 \\
\hline $\mathrm{Cd}^{2+}$ & 2.2 & 0.04 \\
\hline $\mathrm{Hg}^{2+}$ & 2.2 & 0.08 \\
\hline $\mathrm{Cu}^{2+}$ & 2.2 & 0.06 \\
\hline
\end{tabular}

"Ascorbic acid was treated with $0.001 \mathrm{M} \mathrm{NaOH}$ in water bath at 60 "C for $20 \mathrm{~min}$.

acid to uric acid was $5: 1$ when the concentration ratio of ascorbic acid to uric acid was $3.4: 1$, indicating that the oxidation of ascorbic acid at the applied potential $(0.60 \mathrm{~V})$. After ascorbic acid was treated with $0.001 \mathrm{M} \mathrm{NaOH}$ in water bath at $60^{\circ} \mathrm{C}$ for $20 \mathrm{~min}$. the amperometric response ratio of ascorbic acid to uric acid was changed from $5: 1$ to $0.15: 1$ because ascorbic acid was easy to be oxidized in air. especially. in basic and heated condition. In this way, the interferences of ascorbic acid can be eliminated. Much more possible interferents were investigated in this work comparing with the the previous reports. ${ }^{18.31 .23 .88 .25}$ and the results showed that few substances interfere with the determination of uric acid including heavy metal ions due to urease-free at PPy NEEs / GC electrode.

Real sample analysis. Before determination. $1 \mathrm{~mL}$ serum sample was treaed with $20 \mu \mathrm{L} 0.05 \mathrm{M} \mathrm{NaOH}$ in water bath at $60^{\circ} \mathrm{C}$ for $20 \mathrm{~min}^{31}$ PPy NEEs / GC electrode was used to determine uric acid in the real serum samples in the borate buffer solution ( $\mathrm{pH}$ 7.4). Results were compared with those determined by Yunnan Normal University hospital using spectrophotometry (Fig. 9). The correlation coefficient was 0.950 . which indicated that uric acid contents obtained by the two methods agree well with each other.

Repeatability and stability of PPy NEEs / GC electrode. The repeatability of the response current of PPy NEEs / GC electrode was studied at a uric acid concentration of $4.9 \mathrm{mM}$. The variation coefficient was $3.05 \%$ for three successive assays. The stability of the electrode was tested by measuring the response of the sensor with $4.9 \mathrm{mM}$ of uric acid over 90 days. The response current of the sensor decreased to $93.5 \%$ after 90 days. When not in use, the electrode was stored dry at room temperature

\section{Conclusion}

In this paper, PPy nanotubes have been synthesized by chemical oxidative polymerization of pyrrole in the presence of polycarbonate membrane using the technology of diffusion of solutes. Each PPy nanotube is vertically. making each nanotube working as an individual nanoelectrode and entire nanotubes array can be considered as PPy NEEs. The direct detection of PPy NEEs / GC electrode toward uric acid has been studied. The nanostructure improves analytical performances of the corresponding sensors compared to the bare GC electrodes. This PPy NEEs / GC electrode displays high sensitivity quick response to uric acid. good stability and wide linear range. The lifetime of this sensor is much longer than that of biosensor based on uricase.

Ackmowledgments. This work was supported by the Foundation of Science Comnission of Yunnan Province (No.2006 B0028M). the Foundation of Department of Education of Yunnan Province (No.07Z10087).

\section{References}

1. Wang, X. Y.; Kim, Y. G.; Ku, B.-C.; Drew; C; Kumar, T.; Samuelson, L. A Nano. Lett. 2004, 4,331 .

2. Moretto, L. M.: Ugo. P.: Martin, C. R. Anal. Chem 1998, 70. 2163

3. Smela, E. Adv Mater: $2003,15,481$

4. Berdichevshy, Y.; Lo, Y. H. Adv. Hater, 2006, 18, 122.

5. Yuan, Y.; Kim, S. Bull. Korean Chem. Soc. 2008, 29, 1134

6. Yuan, Y, Kim, S. Bull Korean Chem. Soc. 2008, $29,168$.

7. Koopal, C. G. J.: Feiters, M. C.; Nolte, R. I. M. Biosens. Bioelectron. 1992, 7, 461 .

8. Parthasarathy, R. V. Martin, C. R. Nature 1994, $369,298$.

9. Mala Ekanayake, E. M. I.; Preethichandra, D. M. G.; Kaneto, K. Biosens. Bioelection. 2007, 23, 107

10. Ramanavi cius, A.; Ramanavicien'e, A.; Malinallskas, A. Electrochim . Acta 2006, 51,6025.

11. Jiang, X. H.: Lin, X. Q. Anol. Chint Acto 2005, 537, 145

12. Martin, C. R.: Van Dyke, L. S.; Cai, Z. H.; Liang, W. B. J. Am. Chem. Soc. $1990,112,8976$.

13. Martin, C. R. Science 1994, 266, 1961

14. Henández, R.; Richter, L : Semancik, S.: Stranick, S.; Mallonk, T. E. Chem Nater. 2004, 16, 343]

15. Chen, J. H.; Huang, Z. P.; Wang, D. Z.; Yang, S. Y.; Li, W. Z.; Wen, J. G.: Ren, Z. P. Swth liet. 2002, 125, 289

16. Zhong, W. B.; Liu, S. M.; Chen, X. H.; Wang, Y. X.; Yang, W. T. 1 Aaciomol 2006, 39, 3224 .

17. Carswell, A. D. W.: O Rear, E. A.; Grady, B. P. J. Am. Chem. Soc. 2003, 125, 14793

18. Jiang, Y.: Wang, A. Y.: Kan, J. Q. Sens. Actuatons B, Chem. 2007, 124,529

19. Cooper, N.; Khosravan, R.; Erdmanu, C.; Fiene, T; Lee, I. W. J. Chromatogr. B 2006, 837,1 .

20. Canssé, E.: Pradelles, A.: Dirat, B.: Negre-Salvayre, A.; Salvayre, R: Colderc, F. Electrophoresis 2007, 28, 381.

21. Wang, C. Q.; Xu, H. H.; Han, X. G.; Wu, S. G. Chin. J. Ana. Lab. $2007,26,27$

22. Qiao, T. X.; Luo, H. Q.; Li, N. B. Colloils Surf., B: Biointerfaces $2008,62,31$

23. Lin. Y. H.: Lu. F.: Tu. Y.: Ren. Z. F. Nano. Lett. 2004. 4. 191

24. Xian, Y. Z.; Liu, F.: Feng, L. N.: Wu, F. H.: Wang, L.; Jin L. T. Electrochem. Conm. 2007, 9, 773.

25. Erdogdu, G.; Mark, H. B.; Karagozler, A. E. Anal. Lett. 1996, 29, 221 .

26. Malinauskas, A. Sin. Met 1999, 107.75

27. Raoof, T. B.; Ojani, R.; Rashid-Nadimi, S. Electrochm .Acta $2004,+9,271$

28. Jolun, S. A. Electroanal Chent 2005, 579,249

29. Zhang, F. F.; Wang, X. L.; Ai, S. Y.; Sun, Z. D.; Wan, Q.; Zhu, Z. Q.; Xian, Y. Z.; Tin, L. T.; Yamamoto, K Anal Chim Acta 2004, 519.155

30. Yluan, Y.: Saleh Ahammad, A. I; Xu, G. R.: Kim, S.: Lee, I. I. Bull Korean Chem. Soc. 2008. 29. 1883

31. Liu, M.; He, Y. H.; Lü, J. R. Chin. J. Anal. Chem. 2005, 4, 535. 